\title{
Brucellosis and chlamydiosis seroprevalence in goats at livestock-wildlife interface areas of Zimbabwe
}

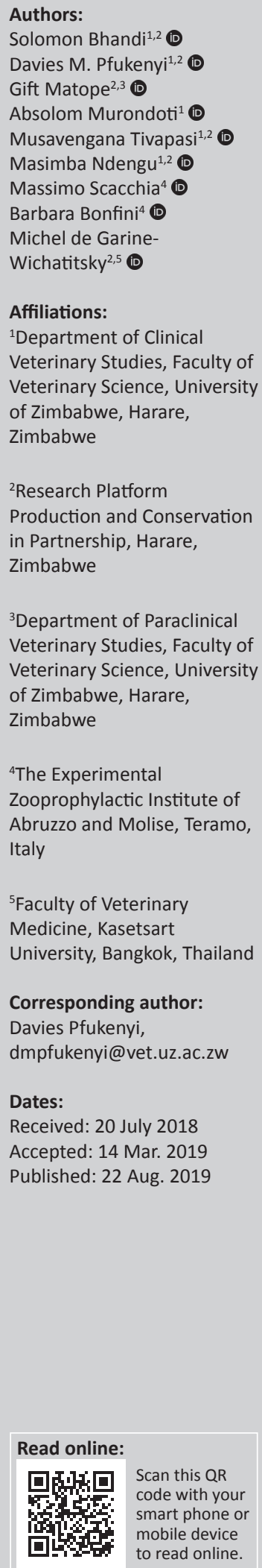

In Zimbabwe, there have been no chlamydiosis and limited brucellosis studies in goats. This study was conducted to determine the seroprevalence and risk factors of the two diseases in goats at three different livestock-wildlife interface areas: porous, non-porous and non-interface in the south-eastern lowveld of Zimbabwe. Collected sera $(n=563)$ were tested for Brucella antibodies using the Rose Bengal plate test (RBPT) and the complement fixation test (CFT); and for Chlamydia abortus antibodies using the CFT. All tested goats were negative for Brucella antibodies. Overall, chlamydial seroprevalence was $22 \%$. The porous $\left[\chi^{2}=9.6\right.$, odds ratio $(\mathrm{OR})=2.6, p=0.002]$ and non-porous $\left(\chi^{2}=37.5, \mathrm{OR}=5.8, p<0.00001\right)$ interfaces were approximately three and six times more likely to be chlamydial seropositive than the noninterface area, respectively. Chlamydial seroprevalence was not associated with sex $\left(\chi^{2}=0.5\right.$, $\mathrm{OR}=1.2, p=0.5)$, abortion history in female goats $\left(\chi^{2}=0.7, \mathrm{OR}=1.3, p=0.4\right)$, keeping goats with cattle $\left(\chi^{2}=0.2, \mathrm{OR}=1.5, p=0.7\right)$ or flock size $\left(\chi^{2}=0.03, \mathrm{OR}=1.4, p=0.9\right)$. Our study provides the first serological evidence of chlamydiosis in goats in Zimbabwe and the results suggest that proximity to wildlife is associated with increased chlamydial seropositivity. Further studies are required to determine the role of chlamydial infection on goat reproductive failure and that of wildlife on C. abortus transmission to domestic ruminants.

Keywords: brucellosis; chlamydiosis; goats; interface; seroprevalence; Zimbabwe.

\section{Introduction}

Goat brucellosis is a chronic infectious disease caused by the gram-negative cocci-bacillus Brucella melitensis (Rossetti et al. 2017). In sub-Saharan Africa, goat Brucella spp. isolation studies are limited as indicated in the exhaustive review by Ducrotoy et al. (2017). This review showed that B. melitensis was isolated infrequently in goats in sub-Saharan African countries such as Kenya, Nigeria, South Africa and Zimbabwe. Literature on Brucella abortus isolation in goats in subSaharan Africa is also scarce with one report in Nigeria (Falade 1981). Similarly, Brucella suis isolations from goats have seldom been reported (Bhaskar Rao, Madhubala \& Rumakrishna Rao 1998), and they have not been further documented (Rossetti et al. 2017). Despite being under control in most industrialised countries, goat brucellosis remains a major problem in the Mediterranean region, the Middle East, Central and Southeastern Asia, sub-Saharan Africa and parts of Latin America (FAO 2010). In Africa, it is endemic in countries in the Mediterranean region and the eastern part of the continent (Rossetti et al. 2017). As brucellosis is considered a neglected disease that significantly affects countries where resources are limited, there are a few studies that measure its economic impact in small ruminants (Rossetti et al. 2017). Despite still remaining a significant burden on goat and human health in the developing world, there is a lack of useful epidemiological data for aiding the design of appropriate control, prevention and eradication strategies. As compared to cattle, there is limited information on goat brucellosis in sub-Saharan Africa (Ducrotoy et al. 2017). Most recent goat seroprevalence studies have been reported in Ethiopia (Asmare et al. 2013; Megersa et al. 2012; Teklue et al. 2013) and South Africa (Simpson et al. 2018).

Except for Australia and New Zealand, Chlamydia abortus is the major cause of abortion in sheep and goats in small ruminant-rearing regions of the world (Rodolakis \& Laroucau 2015). Most cases occur in management systems where animals are closely congregated during the periparturient period (Aitken \& Longbottom 2007). Abortion, in most cases, is the only clinical evidence of C. abortus infection in goats, but concurrent respiratory tract disease, polyarthritis,

How to cite this article: Bhandi, S., Pfukenyi, D.M., Matope, G., Murondoti, A., Tivapasi, M., Ndengu, M., et al., 2019, 'Brucellosis and chlamydiosis seroprevalence in goats at livestock-wildlife interface areas of Zimbabwe', Onderstepoort Journal of Veterinary Research 86(1), a1670. https://doi.org/10.4102/ojvr.v86i1.1670

Copyright: ๑ 2019. The Authors. Licensee: AOSIS. This work is licensed under the Creative Commons Attribution License. 
epididymitis, conjunctivitis and retained placenta have been reported (Matthews 1999). In southern Africa, goat chlamydiosis has been reported in Namibia (Appel, Huebschle \& Krauss 1989; Samkange et al. 2010) and South Africa (Musuka et al. 2001).

Rural communities living on the edge of the Great Limpopo Transfrontier Conservation Area rely mostly on livestock production for their livelihoods (Caron et al. 2013; De GarineWichatitsky et al. 2013; Gadaga et al. 2016; Ndengu et al. 2017a). The boundary fence that was erected to separate wildlife and livestock in the area, as part of the foot-andmouth disease control, has been destroyed; permitting varying degrees of livestock and wildlife contacts (De GarineWichatitsky et al. 2013). Thus, in these areas, humans, domesticated animals and wildlife live in close proximity with the transfer of disease between them being of growing concern (Simpson et al. 2018). Gadaga et al. (2016) and Ndengu et al. (2017a) showed that livestock abortion is a huge challenge and farmers in these areas lack knowledge on possible abortion causes and their transmission pathways and are often at risk of contracting zoonotic infections because of risky animal husbandry practices and poor food handling of animal origin. Brucellosis has been serologically demonstrated in several herbivore wildlife species in the area (Caron et al. 2013; Gomo et al. 2012a; Madsen \& Anderson 1995; Ndengu et al. 2017b) and cattle (Gomo et al. 2012a, 2012b; Ndengu et al. 2017b). Hence, because of the increased human-domestic animals-wildlife contacts in these areas and reliance of the communities on animals and their products for food, it is necessary to investigate goat brucellosis and chlamydiosis in order to highlight the associated public and animal health risks. The results of such studies may help in the design of appropriate control programmes for both animal and human brucellosis and chlamydiosis. In Zimbabwe, there have been limited studies on goat brucellosis (Halliwell, Honhold \& Schlund 1987; Musarandoga \& Muza 2013). To our knowledge, no studies have been conducted previously on goat chlamydiosis in Zimbabwe. Hence, the effects of these diseases on goats, wildlife and humans are largely unknown

This study therefore seeks to investigate the presence and risk factors of brucellosis and chlamydiosis in goats at the livestock-wildlife interface area. The study aimed at establishing if proximity to wildlife is a risk factor for goat brucellosis and chlamydiosis by comparing their seroprevalences in communities representing three distinct areas: porous (unrestricted) and non-porous (restricted by fencing) livestock-wildlife interfaces and non-interface (absent) areas.

\section{Materials and methods \\ Study location}

The study was conducted in the south-eastern lowveld of Zimbabwe, a semi-arid area with annual rainfall below 500-600 mm. The study area falls under agro-ecological region V, a semi-arid land not suitable for rain-fed crop production. It is an extensive farming region with very low and erratic rainfall and therefore generally less suitable for grain and fodder crops. Farming depends on the utilisation of rangelands with extensive livestock production being most appropriate. The estimated goat population in the study area is about 150000 goats and is composed mainly of the indigenous East African breed. Sheep were not considered in this survey as they are an uncommon domestic ruminant in the study area.

Study areas were conveniently selected to include those with a livestock-wildlife interface in the Gonarezhou National Park (GNP) and Malilangwe Conservancy (MC) and another without a livestock-wildlife interface (Figure 1). The livestock-wildlife interfaces were a porous interface with unrestricted livestock-wildlife contact and a non-porous one with a fence preventing direct livestockwildlife contacts (Ndengu et al. 2017a). The selected porous interface was Malipati rural village, which lies directly adjacent to the GNP boundary. A veterinary fence, erected in 1985 to prevent contacts between buffaloes and cattle and foot-and-mouth disease transmission, has been extensively damaged (Dube et al. 2010) permitting wildlife access to human settlements in Malipati and free movement of livestock into the GNP (Chigwenhese et al. 2016). Livestock share grazing and watering sources with wildlife, especially during the dry season when these resources are limited in the Malipati rural village (Miguel et al. 2013; Zengeya et al. 2015). Hence, a significant number of contacts between humans, livestock (including goats) and wildlife are assumed to occur at this interface type, potentially leading to pathogen transmission.

The selected non-porous interface was the Chizvirizvi village which lies on the periphery of the MC. Malilangwe Conservancy is located on the northern boundary of the GNP and it is surrounded by a well-maintained fence, preventing direct contact of wildlife in the conservancy with livestock and humans in the village. The conservancy has the full range of African wild ungulates occurring in the area, while the Chizvirizvi village hosts livestock, mainly cattle and goats. The fence creates a physically defined linear interface, separating wildlife and livestock (Ndengu et al. 2017a). The selected non-interface site was the Chomupani rural area which is located at least $15 \mathrm{~km}$ from the north-western boundary of the GNP. Wild ungulates are reportedly absent in this area and the site was considered to be a control site with no livestock-wildlife interactions as it was far away from the GNP (Ndengu et al. 2017a). Except for proximity to wildlife, all other factors including animal management practices and climatic conditions were similar for the selected study sites.

\section{Goat sampling and sample collection}

In rural communities, a dip tank is a functional unit where disease surveillance and control activities are undertaken. 


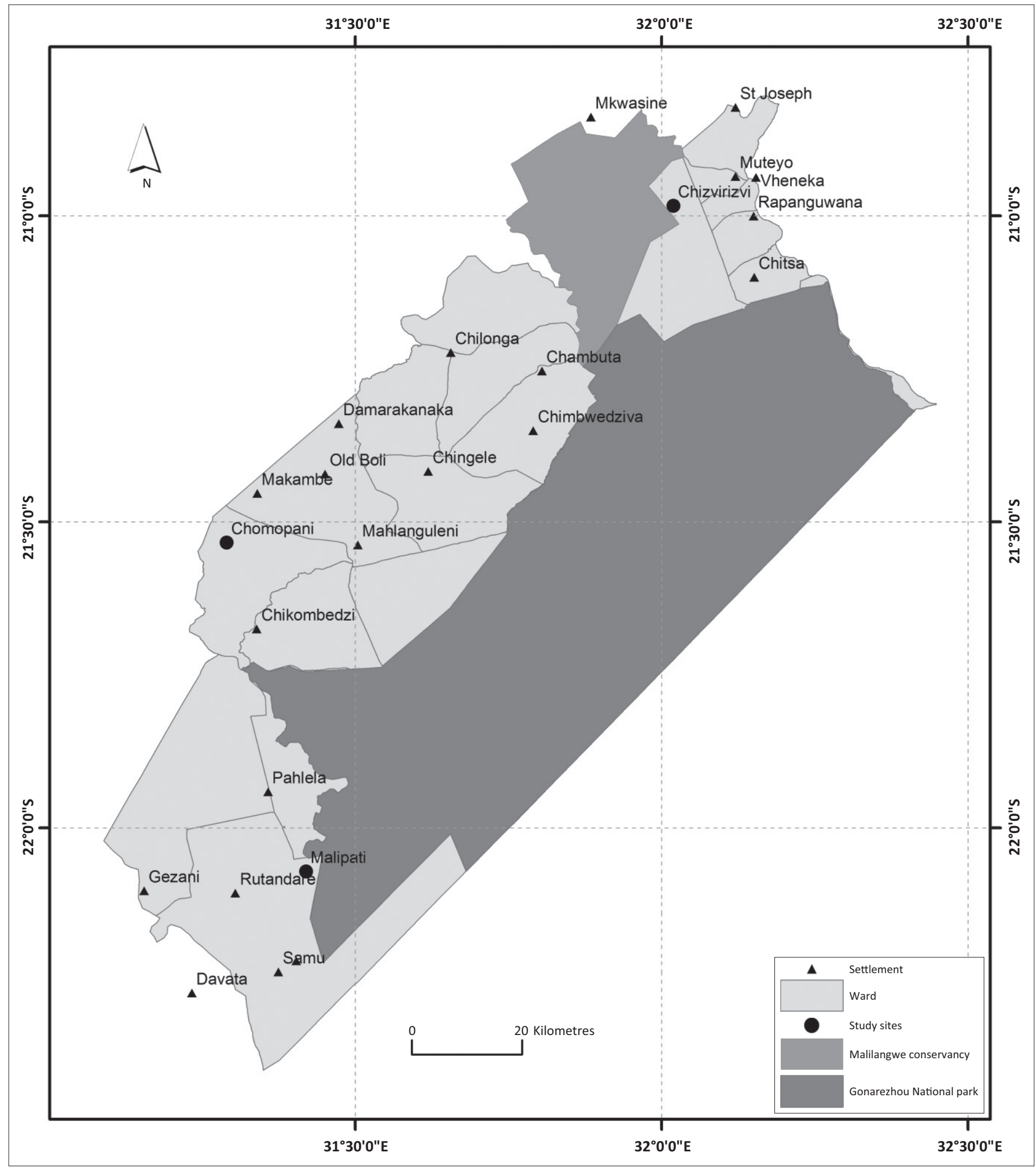

FIGURE 1: Map of the south-eastern Lowveld of Zimbabwe showing the Gonarezhou National Park and the adjacent Malilangwe Conservancy. The three studies are sites represented by big black dots.

A list of all farmers (representing households), who dip their cattle or those who are likely to use (without cattle) any of the dip tanks, is kept at the local veterinary office based in each of the areas (Ndengu et al. 2017a), this was taken as a representative household sampling frame. One dip tank was chosen for each selected study site based on its appropriate location to the interface and these were the Malipati (porous),
Chizvirizvi (non-porous) and Chomupani (non-interface) dip tanks. The total number of farmers (households) listed from the three listed dip tanks was 2028 (Malipati $=697$, Chomupani $=681$ and Chizvirizvi $=650$ ). Based on available resources, 25 households (representing flocks) per site, representing $3.7 \%$ of the total, were selected by a simple random procedure. 
Goat blood samples were collected during the period September 2014-March 2016. Goats at each selected household were identified and sampled using a simple random method. The minimum goat sample size to be sampled was calculated using the formula:

$n=\left[z^{2} \times p(1-p)\right] / e^{2}$,

where

$z$ is the value from standard normal distribution corresponding to the desired confidence level $(z=1.96$ for $95 \%$ confidence interval), $p$ is the estimated prevalence and $e$ is the desired precision (Dohoo, Martin \& Stryhn 2003). We estimated a prevalence of $50 \%$ for brucellosis or chlamydiosis and a $5 \%$ error margin at $95 \%$ confidence level. A minimum of 128 goats was therefore targeted per study site. Blood collection was performed by jugular venipuncture as suggested by Muma et al. (2006). Briefly, each selected goat was physically restrained and $15-20 \mathrm{~mL}$ of blood was collected by jugular venipuncture using a $20 \mathrm{~mL}$ disposable plastic syringe and an 18 gauge needle. The blood was immediately transferred to $4 \mathrm{~mL}$ plain tubes. All blood samples were left to stand for approximately $15 \mathrm{~min}$ in the shade at ambient temperature $\left(2530^{\circ} \mathrm{C}-30^{\circ} \mathrm{C}\right)$ to permit clot separation. Clotted blood samples were then centrifuged at $3000 \mathrm{~g}$ for 15 minutes and $2 \mathrm{~mL}$ of serum were collected into cryo-tubes and stored in liquid nitrogen at $-196^{\circ} \mathrm{C}$ en route to the laboratory. The cold chain was maintained during transportation of samples to the Faculty of Veterinary Science, University of Zimbabwe, and stored at $-20{ }^{\circ} \mathrm{C}$ until analysis. During sample collection, epidemiological data pertaining to each individual were simultaneously collected using a questionnaire. The data included interface type, sex, flock size, reproductive failure history (abortions, still births and weak kids) and keeping of goats with cattle. Laboratory testing of the samples was performed at a World Organization for Animal Health (OIE) reference laboratory, Istituo Zooprofilattico Sperimentale of Abruzzo and Molise (IZSAM), Italy.

\section{Brucellosis testing}

Antibodies to Brucella spp. were tested by using the Rose Bengal plate test (RBPT) and the complement fixation test (CFT). The tests were performed according to standard procedures as detailed in the Manual of Diagnostic Tests and Vaccines for Terrestrial Animals, OIE (2016). Antigens derived from strain 99 B. abortus biovar 1 (AHVLA, Weybridge, UK) were used. The positive and negative antigen reference controls were obtained from IZSAM, Teramo, Italy. The cutoff value for the CFT was $50 \%$ of haemolysis (++) at the $1: 4$ dilution, corresponding to 20 International Units (IU/mL). In this study, a serial testing protocol was used, and thus, a serum was considered positive for antibodies to Brucella spp. if it was positive to both the RBPT and the CFT.

\section{Chlamydiosis testing}

The antibodies to C. abortus were detected by using the CFT. The test was performed using antigen and reference sera provided by IZSAM, Teramo, Italy. The sera were heat inactivated for $30 \mathrm{~min}$ and then diluted in a twofold series to cover a dilution range from $1 / 16$ to $1 / 512$. A total of $25 \mu \mathrm{L}$ of diluted sera, equivalent volume of antigen diluted according to the manufacturer's (IZSAM) instructions and 2U complement were added to the plate wells and incubated at $37{ }^{\circ} \mathrm{C}$ for $30 \mathrm{~min}$. After incubation, $25 \mu \mathrm{L}$ of $2 \%$ sheep red blood cells (SRBCs) sensitised with an equal volume of rabbit anti-SRBC serum diluted to contain $2 \mathrm{U}$ were added and the plate, after further incubation at $37{ }^{\circ} \mathrm{C}$ for $30 \mathrm{~min}$, was centrifuged for $4 \mathrm{~min}$ at $1500 \mathrm{~g}$. Positive and negative reference controls were included in the test. Samples with at least $100 \%$ fixation at the first dilution were considered positive; sera showing less than $100 \%$ fixation as the first dilution were considered negative.

\section{Data analysis}

\section{Descriptive statistics}

The recording and editing of the data was performed in Microsoft Excel ${ }^{\oplus}$ and the descriptive statistics were performed using Stata Version SE 10 for Windows (Stata Corp., College Station, TX, United States [US]). Animal husbandry practices in the study areas allow animals (cattle, goats) to be communally reared with common grazing and water sources. Thus, individual animal seroprevalence estimates with 95\% confidence intervals (CIs) were computed using the Survey Command in Stata, with adjustment for study sites (porous, non-porous and non-interface) and sampling units (flocks). The overall number of brucellosis and chlamydiosis seropositive goats was calculated from the total number of samples tested over the study period and expressed as a percentage. A flock was considered to be positive if at least one goat tested positive for brucellosis or chlamydiosis. Seropositivity was examined in relation to epidemiological data collected. Interface type, sex, flock size, keeping goats with cattle and reproductive failure categories were generated as follows: three for interface type (porous, non-porous and non-interface), two for sex (female goats and male goats), two for flock size $(\leq 20$ and $>20)$, two for keeping goats with cattle (yes and no) and two for reproductive failure history (present and absent). The Chi-square test was used to measure differences between categories and values of $p<0.05$ were considered as significant, while the odds ratio $(\mathrm{OR})$ was used to evaluate the association between seropositivity and the epidemiological variables.

\section{Multivariable logistic regression analyses}

For female goats, a Survey Data Analysis in Stata was used to perform multivariable logistic regression analysis according to Dohoo et al. (2003). The analyses were performed using only data for female goats with complete records $(n=431)$; seven female goats had no data on abortion history. The dependent variable was the chlamydial seropositive status of goats $(0=$ negative, $1=$ positive $)$, while independent variables were the abortion history $(0=$ no, $1=$ yes $)$ and the interface type (porous, non-porous and non-interface). The OR was used to evaluate the association between seropositivity and the epidemiological variables 


\section{Ethical considerations}

Ethical approval for the use of goats and for all protocols used in this study was obtained from the Higher Degrees and Ethical committees of the Faculty of Veterinary Science, University of Zimbabwe and the Department of Veterinary Services, Zimbabwe. The purpose of this study was well explained to all the owners of the goats, who all expressed consent to participate in the study. Standard operating procedures were followed for collection of blood samples (Muma et al. 2006).

\section{Results}

A total of 599 goat samples were collected with 38.1\% (228) from Malipati (porous interface), 32.7\% (196) from Chomupani (non-interface) and 29.2\% (175) from Chizvirizvi (non-porous interface). Of the samples collected, $78.3 \%$ $(469 / 599)$ were from female goats and 21.7\% (130/599) were from male goats. However, 36 samples (1 for Chizvirizvi, 11 for Chomupani and 24 for Malipati) were not tested because of unsuitability or insufficient volumes, resulting in 563 samples being tested and analysed.

\section{Brucellosis seroprevalence}

All of the goat sera tested $(n=563)$ were seronegative for Brucella spp. antibodies.

\section{Chlamydiosis seroprevalence}

\section{Univariable analysis}

The overall individual animal-level seroprevalence was $22 \%$ and it varied significantly $(p<0.05)$ according to interface type (Table 1). At the flock level, the overall seroprevalence was $38.7 \%$ (29/75). Male goats had a higher

TABLE 1: Distribution of chlamydiosis seroprevalence according to interface and sex.

\begin{tabular}{llcccc}
\hline Category & Level & No. tested & Positive & Seroprevalence* & $\mathbf{9 5 \% ~ C l}$ \\
\hline- & All animals & 563 & 124 & 22.0 & $18.7-25.7$ \\
\hline Interface $\dagger$ & $\begin{array}{l}\text { Porous } \\
\text { (Malipati) }\end{array}$ & 204 & 43 & $21.1^{\mathrm{a}}$ & $11.4-30.7$ \\
& $\begin{array}{l}\text { Non-porous } \\
\text { (Chizvirizvi) }\end{array}$ & 174 & 64 & $36.8^{\mathrm{b}}$ & $22.8-50.7$ \\
& $\begin{array}{l}\text { Non-interface } \\
\text { (Chomupani) }\end{array}$ & 185 & 17 & $9.2^{\mathrm{c}}$ & $5.5-12.9$ \\
Sex & Female & 438 & 93 & $21.2^{\mathrm{a}}$ & $15.7-26.7$ \\
\hline & Male & 125 & 31 & $24.8^{\mathrm{a}}$ & $14.4-35.2$ \\
\hline
\end{tabular}

$\mathrm{Cl}$, confidence interval.

*, Figures with a different superscript in the same column for the same category are significantly different at $p<0.05$.

$\dagger$, Porous interface: fence separating the site from park (Gonarezhou National Park) extensively damaged; Non-porous interface: an intact fence separating the site from game park (Malilangwe); non-interface: site far away from the boundary of the park (Gonarezhou National Park). seroprevalence but the difference was not significant $(p=0.5)$ (Table 1). Except for the non-interface site where chlamydial seroprevalence was significantly $(p=0.004)$ higher in female goats with an abortion history, no significant $(p>0.05)$ difference was noted for the other two sites, and overall, the difference was not significant (Table 2). Out of the 75 flocks, 48 (64\%) reported cases of reproductive failure (abortions, still births, weak kids and neonatal deaths).

On univariable analyses, the interface type was significantly associated with chlamydial seropositivity, while sex and abortion history were not. The non-porous interface was 2.2 times and 5.8 times more likely to be seropositive than the porous interface $\left(\chi^{2}=10.7, \mathrm{OR}=2.2,1.4<\mathrm{OR}<3.4, p=\right.$ $0.0011)$ and the non-interface $\left(\chi^{2}=37.5, \mathrm{OR}=5.8,3.2<\mathrm{OR}\right.$ $<10.3, p<0.00001$ ), respectively. Similarly, the porous interface was 2.6 times more likely to be chlamydial seropositivity than the non-interface site $\left(\chi^{2}=9.6, \mathrm{OR}=2.6\right.$, $1.5<\mathrm{OR}<4.8, p=0.002)$. Chlamydial seroprevalence was not associated with sex $\left(\chi^{2}=0.5, \mathrm{OR}=1.2,0.8<\mathrm{OR}<2.0\right.$, $p=0.5)$ and abortion history in female goats $\left(\chi^{2}=0.7, \mathrm{OR}=\right.$ $1.3,0.8<\mathrm{OR}<2.0, p=0.4)$. Similarly, at flock level, there was no association between chlamydiosis seroprevalence and a history of reproductive failure $\left(\chi^{2}=0.2, \mathrm{OR}=1.6\right.$, $0.4<\mathrm{OR}<6.0, p=0.7)$, keeping goats with cattle $\left(\chi^{2}=0.2\right.$, $\mathrm{OR}=1.5,0.5<\mathrm{OR}<4.9, p=0.7)$ and flock size $\left(\chi^{2}=0.03\right.$, $\mathrm{OR}=1.4,0.4<\mathrm{OR}<5.1, p=0.9)$.

Overall, the majority (61.3\%) of seropositive goats had a titre of $1: 16,21 \%$ a titre of $1: 32$ and $17.8 \%$ of them recorded a titre of 1:64 or higher (Table 3). Seven and three seropositive goats from the non-porous interface had titres of 1:128 and 1:256, respectively. None of the seropositive goats from the porous interface and the non-interface areas recorded a titre of 1:256 (Table 3).

\section{Multivariable logistics regression analysis}

The multivariable logistic regression model revealed study sites to be independently associated with the chlamydia seroprevalence of female goats (Table 4). The odds of chlamydia seropositivity increased from Chomupani to Malipati and Chizvirizvi, which are non-interface, porous interface and non-porous interface areas, respectively. Goats from Chizvirizvi were approximately six times $(\mathrm{OR}=6.1,2.5$ $<$ OR < 14.6) more likely to be seropositive for chlamydiosis compared to those from Chomupani (Table 4). Abortion history was not associated with chlamydial seropositivity (Table 4).

TABLE 2: Distribution of chlamydiosis seroprevalence in female goats according to abortion history.

\begin{tabular}{|c|c|c|c|c|c|c|c|c|c|}
\hline \multirow[t]{2}{*}{ Variable } & \multirow[t]{2}{*}{ Level } & \multicolumn{2}{|r|}{ Porous } & \multicolumn{2}{|r|}{ Non-porous } & \multicolumn{2}{|c|}{ Non-interface } & \multicolumn{2}{|r|}{ Overall } \\
\hline & & Tested & $\%$ positive $(95 \% \mathrm{Cl})$ & Tested & $\%$ positive $(95 \% \mathrm{Cl})$ & Tested & $\%$ positive $(95 \% \mathrm{Cl})$ & Tested & $\%$ positive $(95 \% \mathrm{Cl})$ \\
\hline \multirow[t]{2}{*}{ Abortion history } & Yes & 28 & $32.1^{\text {a }}(16.6-52.4)$ & 65 & $27.7^{\mathrm{a}}(17.7-40.4)$ & 67 & $16.4^{\mathrm{a}}(8.9-27.9)$ & 160 & $23.8^{\mathrm{a}}(17.5-31.2)$ \\
\hline & No & 135 & $17.8^{\mathrm{a}}(11.9-25.5)$ & 64 & $45.3^{\mathrm{a}}(33.0-58.2)$ & 72 & $1.4^{\mathrm{b}}(0.1-8.5)$ & 271 & $19.9^{\mathrm{a}}(15.4-25.3)$ \\
\hline
\end{tabular}

$\mathrm{Cl}$, confidence interval.

Figures with a different superscript are significantly different at $p<0.05$.

$\uparrow$. Abortion status was not given for seven animals (porous $=1$, non-porous $=2$, non-interface $=4$ ). 
TABLE 3: Distribution of chlamydiosis seroprevalence according to interface and titre.

\begin{tabular}{|c|c|c|c|c|c|c|c|c|c|c|c|}
\hline \multirow[t]{3}{*}{ Interface } & \multirow[t]{3}{*}{ No. positive } & \multicolumn{10}{|c|}{ Titre } \\
\hline & & \multicolumn{2}{|c|}{$1: 16$} & \multicolumn{2}{|c|}{$1: 32$} & \multicolumn{2}{|c|}{$1: 64$} & \multicolumn{2}{|c|}{$1: 128$} & \multicolumn{2}{|c|}{$1: 256$} \\
\hline & & $n$ & $\%$ & $n$ & $\%$ & $n$ & $\%$ & $n$ & $\%$ & $n$ & $\%$ \\
\hline Non-interface & 17 & 12 & 70.6 & 2 & 11.8 & 2 & 11.8 & 1 & 5.9 & 0 & 0.0 \\
\hline Porous & 43 & 29 & 67.4 & 10 & 23.3 & 2 & 4.7 & 2 & 4.7 & 0 & 0.0 \\
\hline Non-porous & 64 & 35 & 54.7 & 14 & 21.9 & 5 & 7.8 & 7 & 10.9 & 3 & 4.7 \\
\hline Total & 124 & 76 & 61.3 & 26 & 21.0 & 9 & 7.3 & 10 & 8.1 & 3 & 2.4 \\
\hline
\end{tabular}

TABLE 4: Survey multivariable logistic regression analysis of the distribution of chlamydiosis seroprevalence according to interface and abortion history of female goats.

\begin{tabular}{|c|c|c|c|c|}
\hline \multirow[t]{2}{*}{ Variable } & \multirow[t]{2}{*}{ Level } & \multicolumn{3}{|c|}{ Multivariable logistic regression $\dagger$} \\
\hline & & $P$ & Odds ratio & $95 \% \mathrm{Cl}$ \\
\hline \multirow[t]{3}{*}{ Interface type } & $\begin{array}{l}\text { Non-interface } \\
\text { (Chomupani) }\end{array}$ & - & 1.0 & - \\
\hline & Porous (Malipati) & 0.03 & 2.9 & $1.2-7.5$ \\
\hline & $\begin{array}{l}\text { Non-porous } \\
\text { (Chizvirizvi) }\end{array}$ & 0.000 & 6.1 & $2.5-14.6$ \\
\hline \multirow[t]{2}{*}{ Abortion history } & No & - & 1.0 & - \\
\hline & Yes & 0.57 & 1.2 & $0.6-2.5$ \\
\hline
\end{tabular}

$\mathrm{Cl}$, confidence interval.

$\dagger$, Overall data for the model: $p=0.001$, number of observations $=431$.

\section{Discussion}

The RBPT is recommended for brucellosis screening (GarinBastuji \& Blasco 1997), while the CFT is used for its confirmation in small ruminants (Alton 1990; MacMillan 1990) and the two tests were sequentially used in this study. The seronegative results indicated the absence of Brucella spp. in the tested goats. Similar results were reported on goats $(n=353)$ tested earlier in another part of the country (Musarandoga \& Muza 2013). Muma et al. (2006) and Simpson et al. (2018) also showed the absence of brucellosis in goats tested at respective livestock-wildlife interface areas of neighbouring Zambia $(n=280)$ and South Africa $(n=593)$. The absence of Brucella spp. seropositive goats could be that the sampled flocks or goats were naturally free from Brucella infection. However, previous studies in the study area serologically demonstrated brucellosis in cattle and wildlife (Caron et al. 2013; Gomo et al. 2012a, 2012b; Madsen \& Anderson 1995; Ndengu et al. 2017b) and B. abortus was isolated (Gomo et al. 2012b). Elsewhere, in the country, B. melitensis was previously diagnosed (Halliwell et al. 1987) but the goats in which the disease was confirmed were believed to have been illegally translocated across the border from Mozambique (Madsen 1989). One of the isolates was later identified as B. melitensis biovar 1 (Matope et al. 2009). In South Africa, B. melitensis biovar 1 was confirmed in goats (Ribeiro et al. 1990) and B. melitensis biovars 2 and 3 in cattle (Kolo et al. 2018). Besides freedom from the disease, we currently do not have any explanation on the absence of brucellosis seropositive goats from those sampled in the studied areas.

The CFT is the most widely used and recommended procedure for the detection of $C$. abortus in small ruminants (OIE 2012). It was used during the present study as reported elsewhere (Al-Qudah et al. 2004; Musuka et al. 2001; Santos et al. 2012). The test is able to detect antibodies from natural infection and vaccination (OIE 2012). As goat chlamydiosis vaccination is not practised in the study areas, the results indicate natural exposure to chlamydial infection and high titres observed in some of the goats are likely to be an indication of acute infection at or around the time of sampling. This study provides the first serological evidence of $C$. abortus infection in goats in the study areas of Zimbabwe. False-positive results are known to occur because of antigenic cross-reactivity but this is considered to be relatively rare (OIE 2012). Samples with at least 100\% fixation at the first dilution were considered positive including those at a titre of $1 / 16$. A titre of $1 / 16$ could be because of a low-grade infection with C. abortus but it could be non-specific for C. abortus (OIE 2012).

The observed significantly lower goat chlamydial seroprevalence of the non-interface site compared to that of the interface sites (porous and non-porous) suggests that proximity to wildlife is likely associated with an increased chlamydial seropositivity in goats. Serological evidence of chlamydial infection was demonstrated in buffaloes (Syncerus caffer) and impalas (Aepyceros melampus) from the GNP (Ndengu et al. 2018). Contact between livestock and wildlife occurs at the porous interface (Miguel et al. 2013; Zengeya et al. 2015), and hence, wildlife could probably be a source of chlamydial infection in goats and vice versa. Elsewhere, chlamydial seropositivity was found to be higher in wild ruminants residing at the edge of a park where contact with domestic goats and sheep were more likely than those inhabiting the central area (Cubero-Pablo et al. 2000). However, seropositive goats from the noninterface and those from the non-porous interface are unlikely to have contact with wildlife. Goats from the nonporous interface recorded the highest chlamydial seroprevalence and, in contrast to our findings, cattle at the porous interface recorded the lowest chlamydial seroprevalence (Ndengu et al. 2018). These authors suggested a probable independent chlamydial infection cycle in buffaloes; positive sera were recorded in buffalo herds where contact with domestic stock was unlikely. These findings suggest that an independent chlamydial infection cycle is also likely in domestic ruminants. More convincing results could have perhaps been obtained by using more sites for each interface type. Further studies focused on isolates and strain typing will therefore provide more insights on Chlamydia pathogen sharing between domestic and wild ruminants in the study areas.

Ndengu et al. (2018) reported a high seroprevalence of chlamydiosis in cattle in the same study areas and our 
present results showed a moderately high goat chlamydiosis seroprevalence. In Namibia, farm prevalences of $25 \%$ and $86 \%$ have been reported, while individual goat seroprevalences ranged from $2.4 \%$ to $54 \%$ (Appel et al. 1989; Samkange et al. 2010). Elsewhere, very high prevalences of $91.7 \%$ have been reported (Krkalic et al. 2015). The communal sharing of pastures and water sources and keeping together of domestic ruminants practised in the study areas could play a role in the observed high seroprevalence. In addition, the massive environmental contamination which occurs at abortion or parturition when infected female goats shed vast numbers of infective C. abortus (Rodolakis \& Laroucau 2015) forms a major source of infection. The natural route of transmission is considered to be mostly by ingestion or inhalation of infected materials, for instance, when grazing in contaminated pastures (Rodolakis \& Laroucau 2015). Hence, the animal husbandry practices in conjunction with high environmental contamination and various transmission routes are likely to provide a higher risk of chlamydial exposure to domestic ruminants in the study areas.

As was observed elsewhere (Zhao et al. 2012), the risk of chlamydial seropositivity was independent of goat sex. The seroprevalence of $C$. abortus was previously reported to be independent of goat flock size (Al-Qudah et al. 2004; Santos et al. 2012) and this is consistent with our findings. Our results also suggest that owning multiple domestic ruminants is not associated with an increased risk of chlamydiosis seropositivity. The open grazing system practised in the study areas allows mixing of flocks or herds and interspecies grazing; this likely contributes to a uniform spread of chlamydiosis and other infections thereby confounding the effects of flock size and multiple domestic ruminant ownership (Ndengu et al. 2017a). However, the dichotomisation of flock size may result in loss of information and sometimes even inaccurate results (Collins et al. 2016).

Chlamydial infection in goats is known to be associated with abortions (Aitken \& Longbottom 2007; Matthews 1999; Musuka et al. 2001; Nietfeld 2001; Rodolakis \& Laroucau 2015). Abortion history was shown to be associated with a higher risk of chlamydial seropositivity in goats (Samkange et al. 2010; Santos et al. 2012). This is contrary to our observations where history of abortions and other reproductive problems were found not to be associated with chlamydial seropositivity. Similar results were recorded in cattle from the same study areas (Ndengu et al. 2018). In Sardinia (Italy), Masala et al. (2005) reported that C. abortus had a relatively minor role in caprine and ovine abortion. Goats and ewes usually abort once (Rodolakis \& Souriau 1980) and after abortion, the affected animals are immune and are unaffected in subsequent pregnancies (Nietfeld 2001). Data collected on abortion history were restricted to its previous presence or absence and were not specific on whether abortion occurred in the first or subsequent pregnancies. No production and reproduction records were kept by the sampled farmers and data collected relied on recall by the farmers. Hence, lack of accurate data on when abortions occurred could have probably affected the observed association. In addition, low titres of less than 1/32 are non-specific for C. abortus (OIE 2012) and this could also perhaps have biased our findings. The role of chlamydial infection on goat reproductive failure in the country needs further investigation utilising large samples from flocks where reproductive data are accurately captured.

In conclusion, the present study demonstrated the respective absence and presence of brucellosis and chlamydiosis in goats sampled in the south-eastern lowveld of Zimbabwe. Our results suggest that proximity to wildlife is likely associated with an increased chlamydial seropositivity in goats. More studies are required to determine the public health risk of chlamydiosis and the role of chlamydial infection on goat reproductive failure and that of wildlife on C. abortus transmission to goats and other domestic ruminants.

\section{Acknowledgements}

The authors thank the European Union for supporting this research through the EU-DREAM project. This work was conducted within the framework of the Research Platform 'Production and Conservation in Partnership' (http:/ / www. rp-pcp.org). D.M.P., G.M., M.T., M.N. and Md.G.W. were also supported by a grant from the Ministère Français des Affaires Etrangères (FSP-RenCaRe no 2011/36) during the course of this study. The authors also thank the farmers from the Malipati, Chomupani and Chizvirizvi villages, and the staff of the Veterinary Services and National Parks and Wildlife Management Authority (Gonarezhou NP) for their collaboration.

\section{Competing interests}

The authors declare that they have no financial or personal relationships that may have inappropriately influenced them in writing this article.

\section{Authors' contributions}

D.M.P., G.M., A.M., Md.G.W. and S.B. conceived the ideas and designed the study. S.B., M.T. and M.N. collected samples and processed them for laboratory analysis. S.B., M.S. and B.B. conducted laboratory tests. S.B., D.M.P. and G.M. analysed the data and wrote the manuscript. All authors read and approved the final manuscript.

\section{Funding information}

This research was funded by the European Union through the EU-DREAM project.

\section{Data availability statement}

Data sharing is not applicable to this article as no new data were created or analysed in this study. 


\section{Disclaimer}

The views and opinions expressed in this article are those of the authors and do not necessarily reflect the official policy or position of any affiliated agency of the authors.

\section{References}

Aitken, I.D. \& Longbottom, D., 2007, 'Chlamydial abortion', in I.D. Aitken (ed.), Diseases of sheep, pp. 105-112, Blackwell Publishing, Oxford, UK.

Al-Qudah, K.M., Sharif, A., Raouf, R.Y., Hailat, N.Q. \& Al-Dorny, F.M., 2004 'Seroprevalence of antibodies to Chlamydophila abortus shown in Awassi sheep and local goats in Jordan', Veterinary Medicine Czech 49(12), 460-466. https://doi. org/10.17221/5740-VETMED

Alton, G.G., 1990, 'Brucella melitensis', in K. Nielsen \& J.R. Duncan (eds.), Animal brucellosis, pp. 383-409, CRC Press, Boston, MA

Appel, J., Huebschle, O.J. \& Krauss, J., 1989, 'Seroprevalence of Chlamydia psittacispecific antibodies in small stock in Namibia - Epidemiological study with an enzyme linked immunosorbent assay (ELISA)', Journal of Veterinary Medicine Series B - Infectious Diseases, Immunology, Food Hygiene \& Veterinary Public Health 36(6), 447-458. https://doi.org/10.1111/j.1439-0450.1989.tb00627.x

Asmare, K., Megersa, B., Denbarga, Y., Abebe, G., Taye, A., Bekele, J. et al., 2013, 'A study on seroprevalence of caprine brucellosis under three livestock production systems in southern and central Ethiopia', Tropical Animal Health \& Production systems in southern and central Ethiopia,' Tropical Animal

Bhaskar Rao, P., Madhubala, K. \& Ramakrishna Rao, M., 1998, 'Prevalence of viral and bacterial diseases among goats in Andhra Pradesh', Indian Veterinary Journal 75, 924-925.

Caron, A., Miguel, E., Gomo, C., Makaya, P., Pfukenyi, D., Foggin, C. et al., 2013 , 'Relationship between burden of infection in ungulate populations and wildlife/ livestock interfaces', Epidemiology \& Infection 141(7), 1522-1535. https://doi. org/10.1017/S0950268813000204

Chigwenhese, L., Murwira, A., Zengeya, F.M., Masocha, M., Garine-Wichatitsky, M. \& Caron, A., 2016, 'Monitoring African buffalo (Syncerus caffer) and cattle (Bos taurus) movement across a damaged veterinary control fence at a Southern African wildlife/livestock interface', African Journal of Ecology 54(4), 415-423. https://doi.org/10.1111/aje.12288

Collins, G.S., Ogundimu, E.O., Cook, J.A., Manach, Y.L. \& Altman, D.G., 2016, 'Quantifying the impact of different approaches for handling continuous predictors on the performance of a prognostic model', Statistics in Medicine 35(23), 4124-4135. https://doi.org/10.1002/sim.6986

Cubero-Pablo, M.J., Plaza, M., Perez, L., Gonzalez, M. \& Leon-Vizcaino, L., 2000, 'Seroepidemiology of chlamydial infections of wild ruminants of Spain', Journal of Wildlife Diseases 36(1), 35-47. https://doi.org/10.7589/0090-3558-36.1.35

De Garine-Wichatitsky, M., Miguel, E., Mukamuri, B., Garine-Wichatitsky, E., Wencelius, J., Pfukenyi, D.M. et al., 2013, 'Coexisting with wildlife in transfrontie conservation areas in Zimbabwe: Cattle owners' awareness of disease risks and perceptions of the role played by wildlife', Comparative Immunology, Microbiology and Infectious Diseases 36(3), 321-332. https://doi.org/10.1016/j. cimid.2012.10.007

Dohoo, I., Martin, W. \& Stryhn, H., 2003, Veterinary epidemiologic research, pp. 27-407, AVC Inc., Charlottetown, Prince Edward Island.

Dube, T., Murwira, A., Caron, A. \& De Garine-Wichatitsky, M., 2010, 'Preliminary results on the permeability of veterinary fences to buffalo (Syncerus caffer) a cattle in Gonarezhou National Park, Zimbabwe', in K. Ferguson \& J. Hanks (eds.), A review of the environmental, social and economic impacts of game and veterinary fencing in Africa with particular reference to the Great Limpopo and KavangoZambezi Transfrontier Conservation Areas, pp. 228-231, Mammal Research Institute, Pretoria.

Ducrotoy, M., Bertu, W.J., Matope, G., Cadmus, S., Conde-Alvarez, R., Gusi, A.M. et al., 2017, 'Brucellosis in sub-Saharan Africa: Current challenges for management, diagnosis and control', Acta Tropica 165, 179-193. https://doi.org/10.1016/j. actatropica.2015.10.023

Falade, S., 1981, 'Brucellae isolated from goats', Zentralblatt für Veterinarmedizin Reihe B 28(3), 205-209. https://doi.org/10.1111/j.1439-0450.1981.tb01754.x

FAO, 2010, Brucella melitensis in Eurasia and the Middle East, 57 pp., FAO (ed.), FAO Technical meeting in collaboration with WHO and OIE, Rome, Italy.

Gadaga, B.M., Etter, E.M.C., Mukamuri, B., Makwangudze, K.J., Pfukenyi, D.M. \& Matope, G., 2016, 'Living at the edge of an interface area in Zimbabwe: Cattle owners, community chain and health workers' awareness, perception and practices on zoonoses', BMC Public Health 16, 84. https://doi.org/10.1186/ s12889-016-2744-3

Garin-Bastuji, B. \& Blasco, J.M., 1997, 'Caprine and ovine brucellosis (excluding B. ovis infection)', in OIE (ed.), Manual of standards for diagnostic tests and vaccines, $3 \mathrm{rd}$ edn., pp. 350-368, OIE, Paris.

Gomo, C., De Garine-Wichatitsky, M., Caron, A. \& Pfukenyi, D.M., 2012a, 'Survey of brucellosis at the wildlife-livestock interface on the Zimbabwean side of the Great Limpopo Transfrontier Conservation Area', Tropical Animal Health \& Production 44(1), 77-85. https://doi.org/10.1007/s11250-011-9890-5

Gomo, C., Musari, S., De Garine-Wichatitsky, M., Caron, A., Pfukenyi, D.M. \& Van Heerden, $H_{1}, 2012 \mathrm{~b}$, 'Detection of Brucella abortus in Chiredzi district in Zimbabwe', Onderstepoort Journal of Veterinary Research 79(1), Art. \#417, 1-5. https://doi.org/10.4102/ojvr.v79i1.417
Halliwell, R.W., Honhold, N. \& Schlund, J., 1987, 'Zimbabwe brucellosis goat survey', Paper presented at the SADCC Congress on Animal Diseases, Harare, October 1987.

Kolo, F.B., Fasina, F.O., Ledwaba, B., Glover, B., Dongonyaro, B.B., Adesiyun, A.A. et al., 2018, 'Isolation of Brucella melitensis in cattle in South Africa', Veterinary Record 182(23), 668-669. https://doi.org/10.1136/vr.k2450

Krkalic, L., Satrovic, E., Goletic, T., Dzaja, P. \& Severin, K., 2015, 'Chlamydophila abortus infection in a flock of goats in Bosnia and Herzegovina - A case report', Veterinarski Arhiv 85(3), 359-368.

MacMillan, A., 1990, 'Conventional serological tests', in K. Nielsen \& J.R. Duncan (eds.), Animal brucellosis, pp. 153-198, CRC Press Inc., Boca Raton, FL.

Madsen, M., 1989, 'Current status of brucellosis in Zimbabwe', Zimbabwe Veterinary Journal 20, 133-147.

Madsen, M. \& Anderson, E.C., 1995, 'Serologic survey of Zimbabwean wildlife for brucellosis', Journal of Zoo and Wildlife Medicine 26(2), 240-245.

Masala, G., Porcu, R., Sanna, G., Tanda, A. \& Tola, S., 2005, 'Role of Chlamydophila abortus in ovine and caprine abortion in Sardinia, Italy', Veterinary Research Communications 29, 117-123. https://doi.org/10.1007/s11259-005-0842-2

Matope, G., Bhebhe, E., Muma, J.B., Skjerve, E. \& Djonne, B., 2009, 'Characterization of some Brucella species from Zimbabwe by biochemical profiling and AMOS PCR', BMC Research Notes 2, 261. https://doi.org/10.1186/1756-0500-2-261

Matthews, J., 1999, 'Abortion', in J.G. Matthews (ed.), Diseases of the goat, pp. 22-36, Blackwell Science, Oxford.

Megersa, B., Biffa, D., Abunna, F., Regassa, A., Godfroid, J. \& Skjerve, E., 2012, \& Infection 140(5), 887-896. https://doi.org/10.1017/S0950268811001178

Miguel, E., Grosbois, V., Caron, A., Cornélis, D., Boulinier, T., Fritz, H. et al., 2013 Contacts and foot and mouth disease transmission from wild to domestic bovines in Africa', Ecosphere 4(4), 51. https://doi.org/10.1890/ES12-00239.1

Muma, J.B., Samui, K.I., Siamudaala, V.M., Oloya, J., Matope, G., Omer, M.K. et al., 2006, 'Prevalence of antibodies to Brucella spp. and individual risk factors of infection in traditional cattle, goats and sheep reared in livestock-wildlife interface areas of Zambia', Tropical Animal Health \& Production 38(3), 195-206. https:// doi.org/10.1007/s11250-006-4320-9

Musarandoga, C. \& Muza, B., 2013, 'Seroprevalence of brucellosis in small ruminants and farmer awareness of the disease on selected farms in Beatrice, Zimbabwe', BVSc dissertation, University of Zimbabwe.

Musuka, G.N., Meiswinkel, R., Baylis, M., Kelly, P.J. \& Mellor, P.S., 2001, 'Chlamydia abortion in goats in the Umzimkulu district of Eastern Cape', Journal of the South African Veterinary Association 72(2), 62-63.

Ndengu, M., De Garine-Wichatitsky, M., Pfukenyi, D.M., Tivapasi, M., Mukamuri, B. \& Matope, G., 2017a, 'Assessment of community awareness and risk perceptions of zoonotic causes of abortion in cattle at three selected livestock-wildlife interface areas of Zimbabwe', Epidemiology \& Infection 145(7), 1304-1319. https://doi. org/10.1017/S0950268817000097

Ndengu, M., Matope, G., De Garine-Wichatitsky, M., Tivapasi, M., Scacchia, M., Bonfini, B. et al., 2017b, 'Seroprevalence of brucellosis in cattle and selected wildlife species at selected livestock/wildlife interface areas of the Gonarezhou National Park, Zimbabwe', Preventive Veterinary Medicine 146, 158-165. https:// doi.org/10.1016/j.prevetmed.2017.08.004

Ndengu, M., Matope, G., De Garine-Wichatitsky, M., Tivapasi, M., Scacchia, M. Bonfini, B. et al., 2018, 'Seroprevalence of chlamydiosis in cattle and selected wildlife species at selected livestock/wildlife interface areas of the Gonarezhou National Park, Zimbabwe', Tropical Animal Health \& Production 50(5), 1107-1117. https://doi.org/10.1007/s11250-018-1536-4

Nietfeld, J.C., 2001, 'Chlamydial infections in small ruminants', Veterinary Clinics North America: Food Animal Practice 17(2), 301-314. https://doi.org/10.1016/S07490720(15)30030-X

OIE, 2012, 'Enzootic abortion in ewes (ovine chlamydiosis) (infection with Chlamydophila abortus)', Manual of Standards for Diagnostic Tests and Vaccines for Terrestrial Animals, OIE, viewed 30 May 2017, from http://www.oie.int/ fileadmin/Home/eng/Health_standards//tahm/2.07.06_ENZ_ABOR.pdf $>$.

OIE, 2016, 'Brucellosis (Brucella abortus, B. melitensis and B. Sui) (infection with $B$. abortus, B. melitensis and B. suis)', Manual of Standards for Diagnostic Tests and Vaccines for Terrestrial Animals, World Organization for Animal Health; 2016, viewed 30 May 2017, from http://www.oie.int/fileadmin/Home/eng/Health_ standards/tahm/2.01.04_BRUCELLOSIS.pdf $>$.

Ribeiro, L.M.M., Herr, S., Chaparro, F. \& Van Der Vyver, F.H., 1990, 'Isolation and serology of B. melitensis in a flock of goats in Central R.S.A.', Onderstepoort Journal of Veterinary Research 57(2), 143-144.

Rodolakis, A. \& Laroucau, K., 2015, 'Chlamydiaceae and chlamydial infections in sheep and goats', Veterinary Microbiology 181(1-2), 107-118. https://doi. org/10.1016/j.vetmic.2015.07.010

Rodolakis, A. \& Souriau, A., 1980, 'Clinical evaluation of immunity following experimental or natural infection of ewes with Chlamydia psittaci (var ovis)', Annales Recherches Veterinaires 11(2), 215-223.

Rossetti, C.A., Arenas-Gamboa, A.M. \& Maurizio, E., 2017, 'Caprine brucellosis: A historically neglected disease with significant impact on public health', PLOS Neglected Tropical Diseases 11(8), e0005692. https://doi.org/10.1371/journal.pntd.0005692

Samkange, A., Katsande, T.C., Tjipura-Zaire, G. \& Crafford, J.E., 2010, 'Seroprevalence survey of Chlamydophila abortus infection in breeding goats on commercial farms in the Otavi Veterinary District, Northern Namibia', Onderstepoort Journal of Veterinary Research 77(1), Art. \#1, 1-5. https://doi.org/10.4102/ojvr.v77i1.1

Santos, C.S.A.B., Piatti, R.M., Azevedo, S.S., Alves, C.J., Higino, S.S.S., Silva, M.L.C.R. et al ., 2012, 'Seroprevalence and risk factors associated with Chlamydophila abortus infection in dairy goats in the Northeast of Brazil', Pesquisa Veterinaria Brasileira 32(11), 1082-1086. https://doi.org/10.1590/S0100-736X2012001100002 
Simpson, G., Marcotty, T., Rouille, E., Matekwe, N., Letesson, J.J. \& Godfroid, J., 2018 , "Documenting the absence of brucellosis in cattle, goats and dogs in a "One (4), 903-906. https://doi.0, 5/10.1007/s11250-017-1495-1

Teklue, T., Tolosa, T., Tuli, G., Beyene, B. \& Hailu, B., 2013, 'Sero-prevalence and risk factors study of brucellosis in small ruminants in Southern Zone of Tigray Region, Northern Ethiopia', Tropical Animal Health \& Production 45(8), 1809-1815. https://doi.org/10.1007/s11250-013-0439-7
Zengeya, F.M., Murwira, A., Caron, A., Cornélis, D., Gandiwa, P. \& De GarineWichatitsky, M., 2015, 'Spatial overlap between sympatric wild and domestic herbivores links to resource gradients', Remote Sensing Applications: Society and Environment 2, 56-65. https://doi.org/10.1016/j.rsase.2015.11.001

Zhao, G., Shang, C., Zhao, Y., Gao, M., Fan, G., Tian, T. et al., 2012, 'Seroprevalence of chlamydial infection in dairy goats in Shaanxi Province, Northwestern China', African Journal of Biotechnology 11(7), 1796-1799. 